\title{
Rancang Bangun Sistem Informasi Pemesanan Custom Furniture Berbasis Website
}

\author{
Damasius Wikaryana Utama1, I Gusti Lanang Agung Raditya Putra², I Putu Satwika ${ }^{3}$ \\ 1,2,3Program Studi Sistem Informasi STMIK Primakara \\ Jalan Tukad Badung Nomor 135, Denpasar, Bali, 03618956085 \\ angelone191@gmail.com, la.raditya27@gmail.com, satwika@primakara.ac.id
}

\begin{abstract}
Information is the king pin in business. Companies challenge their self to get an actual and factual information to be exist and win the tender. Companies are forced to use an up-to-date technology to produce the information needed. Especially in custom furniture company that has a long business process. It starts from measuring, modelling, budgeting, quotation, remeasuring, quality control, budget realization, until invoice printing. All of those processes must be organized in 1 management, so the custom furniture company can provide the actual and factual information for their customers. CV. Bali Interio is one of the company run in custom furniture business. This company has problems in their business process, it starts from the unorganized documents, slow processing documents que, messing measuring schedule, online buyer that doesn't have an online media to buy, and the customers who want to monitor their order online. Based on the problems, it can be concluded that CV. Bali Interio needs a computerized system to solve the problems so it can give the best information needed for company or customer.
\end{abstract}

Keywords: Custom Furniture, Sistem Informasi Pemesanan, Web Based Information System, Online Ordering, Document Production.

\begin{abstract}
Abstrak
Informasi merupakan poin inti dalam dunia bisnis. Perusahaan-perusahaan berlomba-lomba untuk mendapatkan informasi yang akurat dan cepat, sehingga dapat tetap bertahan dan memenangkan persaingan. Perusahaan-perusahaan dipicu untuk menggunakan teknologi yang maju serta dapat menghasilkan informasi yang akurat dan cepat. Khususnya pada perusahaan custom furniture yang mempunyai proses bisnis yang panjang. Mulai dari proses pengukuran, pembuatan model, rab, penawaran produk (quotation), pengurukuran ulang, quality control, realisasi rab serta invoice. Semua proses tersebut harus tergoranisir dalam 1 manajemen sehingga suatu perusahaan custom furniture dapat memberikan informasi yang cepat dan akurat. CV. Bali Interio merupakan salah satu perusahaan yang bergerak di bidang custom furniture. Perusahaan tersebut mempunyai permasalahan pada proses bisnis mulai dari penempatan dokumen yang tidak terstruktur, pembuatan dokumen yang kurang cepat, jadwal pengukuran yang kurang disiplin, serta konsumen yang ingin memesan secara online dan ingin mengetahui seberapa jauh proses pembuatan produk yang mereka pesan. Berdasarkan permasalahan tersebut, CV. Bali Interio memerlukan sebuah sistem informasi pemesanan yang terkomputerisasi untuk mengatasi masalah yang terjadi agar mampu mengolah data serta memberikan informasi yang cepat, akurat dan tepat waktu saat dibutuhkan.
\end{abstract}

Kata kunci: Custom Furniture, Sistem Informasi Pemesanan, Sistem Informasi Berbasis Website, Pemesanan Online, Pembuatan Dokumen.

\section{PENDAHULUAN}

Informasi merupakan poin inti dalam dunia bisnis. Perusahaanperusahaan berlomba-lomba untuk mendapatkan informasi yang akurat dan 
cepat, sehingga dapat tetap bertahan dan memenangkan persaingan keras [1][2]. Salah satu perubahan yang terjadi pada dunia teknologi informasi adalah sebuah sistem informasi di suatu perusahaan. Penggunaan sistem informasi pada sebuah perusahaan dapat mempercepat berbagai proses di suatu perusahaan seperti pembuatan laporan transaksi dan dokuem lainnya. CV. Bali Interio merupakan salah satu perusahaan yang bergerak dalam bidang penjualan furniture dan custom furniture. Perusahaan ini bertempat di Jalan Raya Kerobokan No, 78 Banjar Taman Kerobokan Kelod, Denpasar, Bali. Perusahaan ini juga mempunyai pabrik dalam pembuatan furniture yang bertempat di Monang-maning, Denpasar, Bali.

Berdasarkan hasil wawancara dengan Bapak Marthunus Fahrizal selaku pimpinan CV. Bali Interio, masalah utama yang terjadi pada CV. Bali Interio adalah pada pembuatan dokumen dalam proses bisnis seperti quotation, spk, sales order, bill of material tidak dapat dibuat tepat waktu diakibatkan proses pembuatan dokumen tersebut dilakukan secara terpisah. Padahal dokumen tersebut hanya membutuhkan RAB yang telah dibuat. Kendala lain terjadi pada pengarsipan model. Model-model disimpan pada email dan google drive secara acak mengakibatkan model tersebar dan susah untuk mendapatkan model tertentu saat dibutuhkan. Masalah kecil seperti ini kerap mengakibatkan keterlambatan proses pembuatan dokumen yang berdampak pada customer sehingga loyalitas customer akan berkurang.

Salah satu solusi yang dapat memecahkan masalah tersebut adalah penggunaan sistem informasi. Dalam jurnal yang ditulis oleh Kusnawi yang berjudul "Perancangan Sistem Informasi Pemesanan Meja dan Makanan (Studi Kasus Restoran ABC)" dikatakan bahwa sistem informasi pemesanan online tersebut dapat memberikan solusi terhadap permasalahan utama yang dihadapi oleh resotran ABC yaitu pembuatan dokumen yang [3-6]. Maka dari itu CV Bali Interio memerlukan sebuah sistem yang terkomputerisasi untuk mengatasi masalah yang terjadi, agar mampu mengolah data serta memberikan informasi yang cepat, akurat dan tepat waktu saat dibutuhkan serta proses pemesanan produk dapat dilakukan secara online.

\section{METODOLOGI PENELITIAN}

\subsection{Pemesanan}

Pemesanan barang dan jasa adalah suatu kegiatan transaksi yang menyatakan keinginan atau rencana untuk memiliki atau membeli barang dan jasa tersebut sebelum melakukan transaksi finasial yakni berupa pembayaran finasial terhadap produk atau jasa yang diinginkan [8].

\subsection{Sistem Informasi Pemesanan}

Sistem informasi pemesanan merupakan suatu sistem informasi yang mampu mengatur lalu lintas transaksi pemesanan yakni proses perencanaan suatu produk atau jasa sebelum kemudian diolah oleh sistem terorganisasi yang dilanjutkan dengan transaksi finansial yaitu berupa pembayaran tunai terhadap suatu produk atau jasa yang diinginkan[9-11]. 


\subsection{Custom Furniture}

Mebel atau furniture merupakan fasilitas atau sarana bagi berbagai kegiatan manusia dalam sebuah ruangan. Kata Mebel berasal dari kata Meubel (bahasa Belanda), meubles (bahasa Perancis), mobler (bahasa Jerman), mobilia (bahasa Italia) sedangkan dalam bahasa Inggris dikenal istilah furniture.

Custom berarti membuat atau mengubah sesuatu sesuai dengan kebutuhan pembeli, pengguna atau spesifikasi individu tertentu. Jadi dapat diartikan custom furniture adalah sebuah sarana untuk berbagai kegiatan manusia dalam sebuah ruangan yang dapat dibuat sesuai dengan kebutuhan pembeli [8].

\subsection{Metode Penelitian}

Adapun metodologi penelitian yang digunakan pada penelitian ini adalah metode SDLC (System Depelopement Life Cycle) [12]. SDLC merupakan metodologi klasik yang digunakan untuk mengembangkan, memelihara dan menggunakan sistem informasi [13-14]. Metode ini menggunakan pendekatan sistem yang disebut pendekatan air terjun (waterfall approach) yang menggunakan beberapa tahapan dalam mengembangkan sistem. Adapun tahapan dalam SDLC (System Development Life Cycle) sebagai berikut:

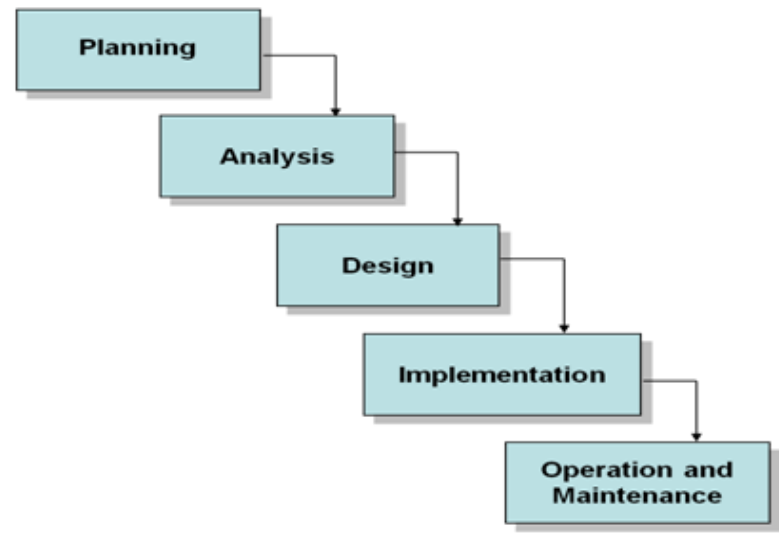

Gambar 1 Metode SDLC Model Waterfall

a. Tahap Perencanan Sistem (System Planning)

Tahap perencanaan adalah tahap awal pengembangan sistem. Dalam penelitian ini sebelumnya telah dilakukan perencanaan manajemen proyek (project management plan) yang memuat perkiraan kebutuhankebutuhan sumber daya seperti perangkat fisik, manusia, metode.

b. Tahap Analisis Sistem (System Analysis)

Data yang dikumpulkan oleh penulis yaitu dalam bentuk data kualitatif yang diperoleh dari hasil studi literatur dari berbagai penelitian serupa serta melakukan wawancara dengan owner CV. Bali Interio. Kemudian data tersebut digunakan sebagai acuan dalam pembuatan fitur-fitur sistem. 
c. Tahap Perancangan/Desain Sistem (System Design).

Tahap desain sistem adalah tahap setelah analisis sistem yang menentukan proses dan data yang diperlukan oleh sistem. Dalam penelitian ini dilakukan perancangan sistem dengan membuat alur sistem menggunakan DFD (Data Flow Diagram) dan ERD (Entity Relationship Diagram).

d. Tahap Penerapan/Implementasi Sistem (System Implementation).

Tahap implementasi merupakan konversi dari hasil rancangan menjadi bentuk sistem menggunakan script/code. Penulis menggunakan bahasa markup HTML5 (HyperText Markup Language versi 5) \& CSS3 (Cascading Style Sheet versi 3). Bahasa Pemrograman PHP versi 7, Javascript, dengan text editor pendukung Sublime, serta basis data yang di gunakan adalah MySQL.

e. Tahap Percobaan (Testing).

Melakukan uji coba terhadap semua fungsi-fungsi sistem, agar sistem bebas dari eror dan hasilnya sesuai dengan kebutuhan yang sudah didefinisikan sebelumnya. Pada tahap ini proses testing dilakukan dengan menggunakan metode Black-Box Testing.

f. Analisis Efektivitas Sistem

Melakukan analisis terhadap efektivitas sistem terkait kualitas sistem, kualitas informasi, kepuasan pengguna, dan manfaat sistem bagi pengguna. Untuk mengetahui seberapa besar efektivitas dan kegunaan sistem dilakukan dengan wawancara mendalam kepada 5 pegawai CV. Bali Interio yang selanjutnya diolah dan dianalisis dengan teknik penarikan kesimpulan.

\section{HASIL DAN PEMBAHASAN}

Pengerjaan rancang bangun sistem informasi pemesanan custom furniture pada CV. Bali Interio, dilakukan dengan menerapkan pendekatan sistem menggunakan metode SDLC Waterfall model yang terdiri dari tahap analisis, desain, implementasi, testing dan evaluasi.

\subsection{Tahap Perencanaan}

Dari tahapan ini diperoleh data primer dan data sekunder. Data primer adalah data yang diperoleh langsung dari narasumber dan objek penelitian. Sedangkan data sekunder adalah data yang diperoleh dari studi kepustakaan. Teknik yang digunakan dalam pengumpulan data ini, yaitu observasi atau pengamatan langsung terhadap objek penelitian serta wawancara mendalam atau in-depth interview kepada narasumber dari perusahaan serta studi pustaka yaitu membaca dan menelaah teori-teori yang berkaitan dengan kegiatan evaluasi sistem informasi.

\subsection{Tahap Analisis}

Setelah penulis menyimpulkan hasil wawancara kepada manager CV. Bali Interio serta mengetahui proses bisnis CV. Bali Interio secara keseluruhan, maka dapat diketahui fitur-fitur sitem informasi pemesanan custom furniture $\mathrm{CV}$. Bali Interio. 


\subsection{Tahap Desain}

Tahap desain atau tahap perancangan penelitian dimulai dari pembuatan rancangan sistem berupa diagram arus data, ERD dan rancangan basis data.

\section{A. Data Flow Diagram}

Diagram arus data menggambarkan arus data yang terdapat pada sistem informasi pemesanan custom furniture CV. Bali Interio. Berikut diagram arus data pada sistem informasi pemesanan custom furniture $\mathrm{CV}$. Bali Interio.

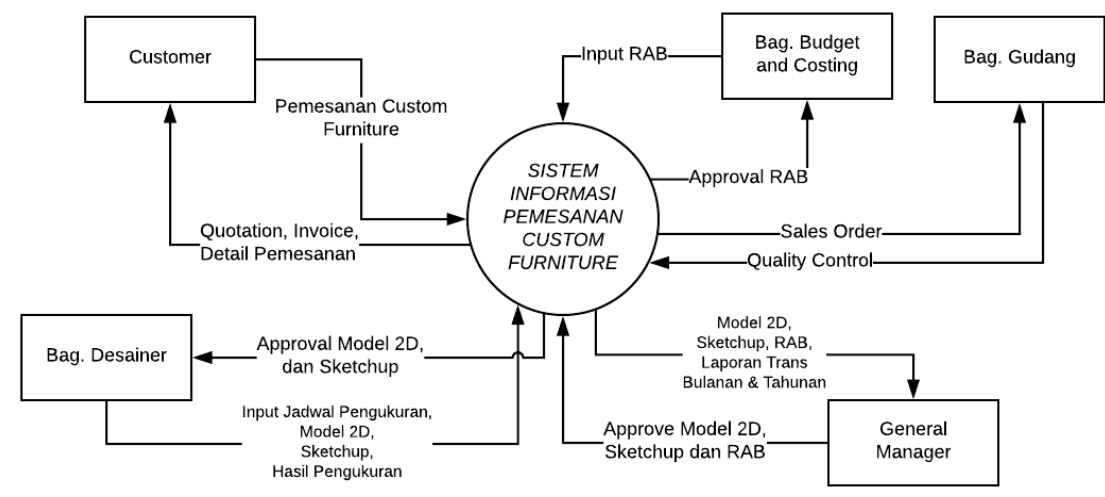

Gambar 2 Diagram Konteks Sistem Informasi Pemesanan Custom Furniture

\section{B. Entity Relationship Diagram}

Diagram Entitas menggambarkan data-data atau objek-objek yang dibuat berdasarkan dan berasal dari dunia nyata yang disebut entitas (entity) serta hubungan (relationship) antar entitas-entitas tersebut dengan menggunakan beberapa notasi.

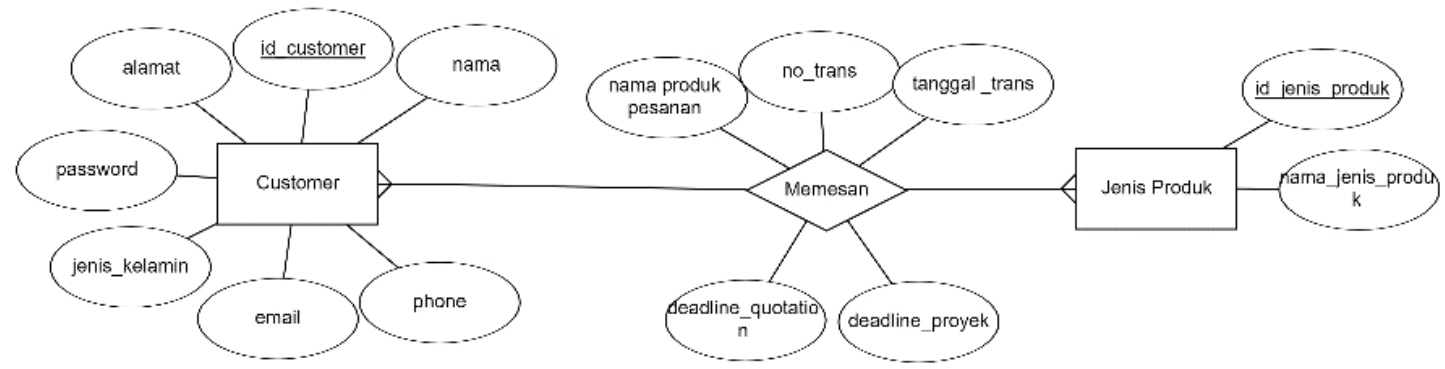

Gambar 3 ERD Pemesanan Custom Furniture

\section{Rancangan Basis Data}

Setelah perancangan diagaram entitas selesai, maka didapatkan rancangan basis data berdasarkan diagram entitas tersebut. 
Jurnal Sains Komputer \& Informatika (J-SAKTI)

Volume 3 Nomor 1 Maret 2019, pp. 53-67

ISSN:2548-9771/EISSN:2549-7200

http://tunasbangsa.ac.id/ejurnal/index.php/jsakti

\begin{tabular}{|l|}
\hline transaksi_pemesanan \\
\hline *id_trans \\
no_trans \\
* customer_id \\
tanggal_trans \\
bulan_trans \\
trans_statuis \\
deadline_quotation \\
deadline_proyek \\
pengkuran \\
gambar \\
$\star \star$ id_estimasi \\
created_at \\
$\star \star$ staff_id \\
proyek_status \\
\hline
\end{tabular}

Gambar 4 Rancangan Tabel

Pemesnaan

\begin{tabular}{|l|}
\hline \multicolumn{1}{|c|}{ pemodelan_2d_d } \\
\hline * id_d_model2d \\
** id_model_3d \\
model_file \\
\hline
\end{tabular}

model versi

** staff_id

created_at

** approved_by

approved_tgl

Gambar 6 Rancangan Tabel Model

2D

\begin{tabular}{|l|}
\hline \multicolumn{1}{|c|}{ sales_order } \\
\hline * id \\
** id_trans \\
** id_quotation \\
notes \\
date_deal \\
\hline
\end{tabular}

Gambar 8 Rancangan Tabel Sales Order

\begin{tabular}{|l|}
\hline \multicolumn{1}{|c|}{ customer_login } \\
\hline${ }^{*}$ customerLogin_id \\
${ }^{\star *}$ customer_id \\
customerLogin_username \\
customerLogin_password \\
customerLogin_salt \\
\hline
\end{tabular}

\begin{tabular}{|l|}
\hline \multicolumn{1}{|c|}{ customer } \\
\hline${ }^{*}$ customer_id \\
customer_nama \\
customer_tgllahir \\
customer_alamat \\
customer_phone \\
customer_email \\
customer_jk \\
created_at \\
update_at \\
** staff_id
\end{tabular}

Gambar 5 Rancangan Tabel

Customer

\begin{tabular}{|c|}
\hline quotation_d \\
\hline * id_quotation_d \\
\hline ** id_quotation \\
\hline ** id rab \\
\hline
\end{tabular}

Gambar 7 Rancangan Tabel Quotation

\begin{tabular}{|l|}
\hline \multicolumn{1}{|c|}{ invoice } \\
\hline * id \\
no_invoice \\
** id_trans \\
percent_invoice \\
status_invoice \\
lunas_date \\
\hline
\end{tabular}

Gambar 9 Rancangan Tabel Invoice

\subsection{Tahap Implementasi}

Rancangan dan implementasi antarmuka sistem menggambarkan desain sistem yang meliputi tata letak, besar kecil teks dan paduan warna. Rancangan dan implementasi antarmuka sistem dibagi menjadi dua yaitu antarmuka untuk pemesan/member dan antarmuka untuk administrator. 


\section{A. Halaman Untuk Pemesan/Member}

Halaman untuk pemesan/member adalah halaman yang dapat diakses oleh pemesan/member. Hasil implementasi halaman untuk pemesan dapat dilihat sebagai berikut.

\section{A.1 Halaman Register dan Login Member}

Halaman register member merupakan halaman yang digunakan oleh pengguna publik untuk mendaftarkan diri menjadi member. Sedangkan halaman login member merupakan halaman yang digunakan oleh pengguna publik yang telah menjadi member untuk masuk ke sistem.

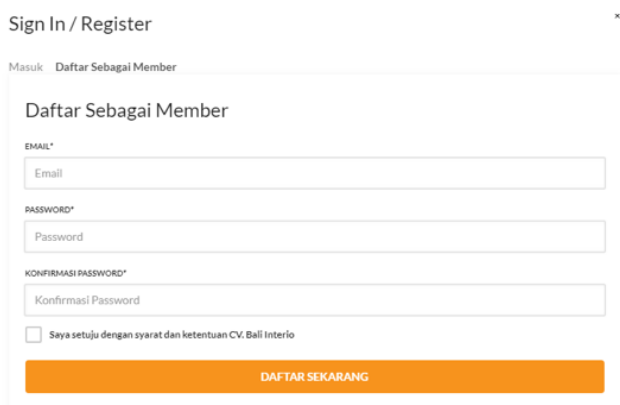

Gambar 10 Halaman Register Member

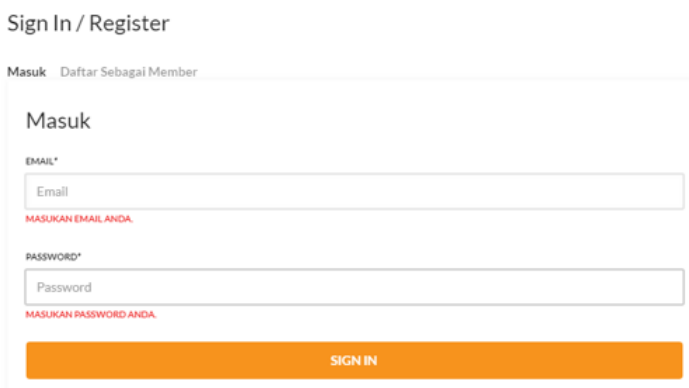

Gambar 11 Halaman Login Member

\section{A.2 Halaman Pemesanan Produk}

Halaman ini merupakan halaman yang digunakan member untuk melakukan pemesanan produk custom furniture. Member cukup memilih produk yang ingin dipesan, lalu memberikan data berupa nama produk custom dan jumlah produk yang ingin dipesan.

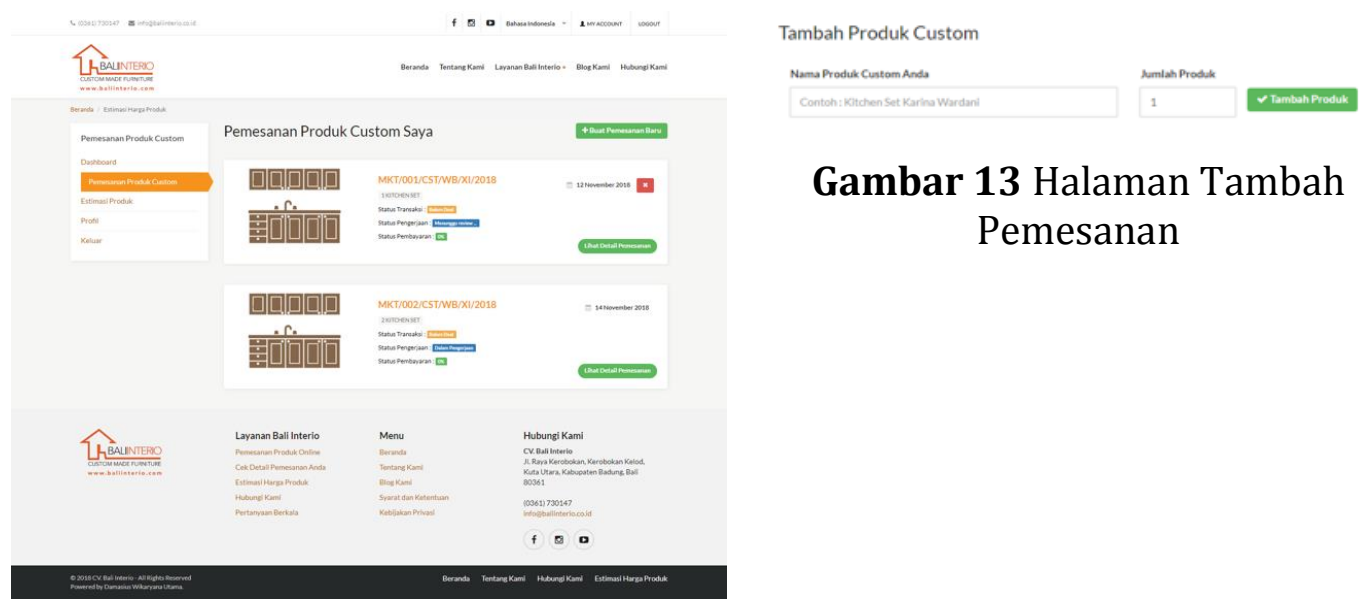

Gambar 12 Halaman Pemesanan

Produk 


\section{A.3 Halaman Tracking dan Detail Pemesanan}

Halaman detail pemesanan merupakan halaman yang dapat diakses oleh member ataupun pengguna yang belum mendaftarkan diri. Halaman ini berfungsi untuk melihat transaksi pemesanan produk secara detail. Mulai dari informasi pengguna, produk yang dipesan, harga sementara, harga final, penjadwalan pengukuran, dokumen penawaran, proses pembuatan dan tagihan atau invoice.

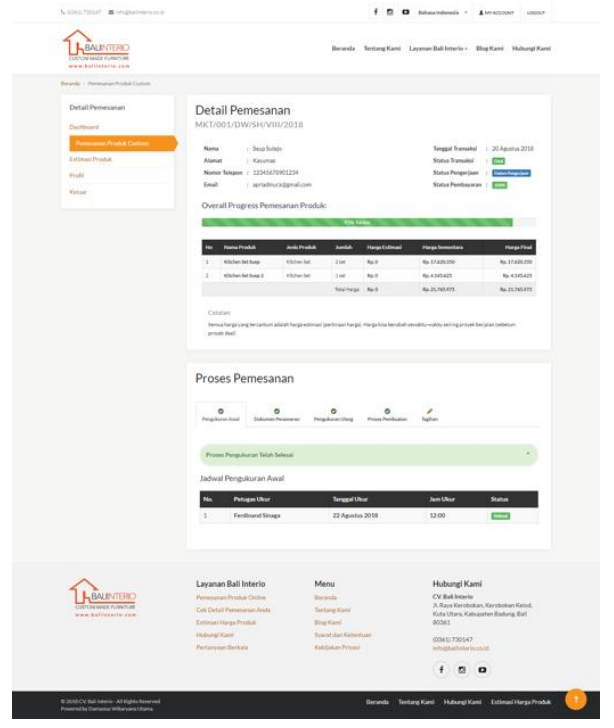

Gambar 13 Halaman Detail Pemesanan

\section{B. Halaman Untuk Administrator}

Halaman untuk administrator merupakan halaman yang dapat diakses oleh administrator. Hasil implementasi halaman untuk administrator dapat dilihat sebagai berikut.

\section{B.1 Halaman Login Administrator}

Halaman login administrator digunakan oleh administrator yang sudah memiliki akun aktif. Hasil implementasi halaman login administrator dapat dilihat pada gambar berikut.

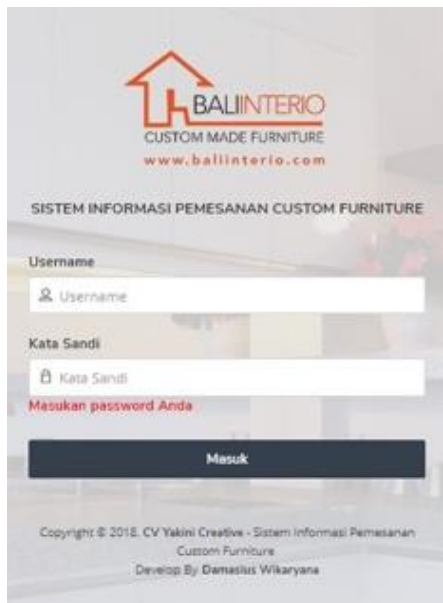

Gambar 14 Halaman Login Administrator 


\section{B.2 Halaman Tambah Pemesanan}

Halaman tambah pemesanan merupakan halaman yang digunakan administrator untuk menambahkan pemesanan secara langsung/direct. Hasil implementasi halaman tambah pemesanan dapat dilihat pada gambar berikut.

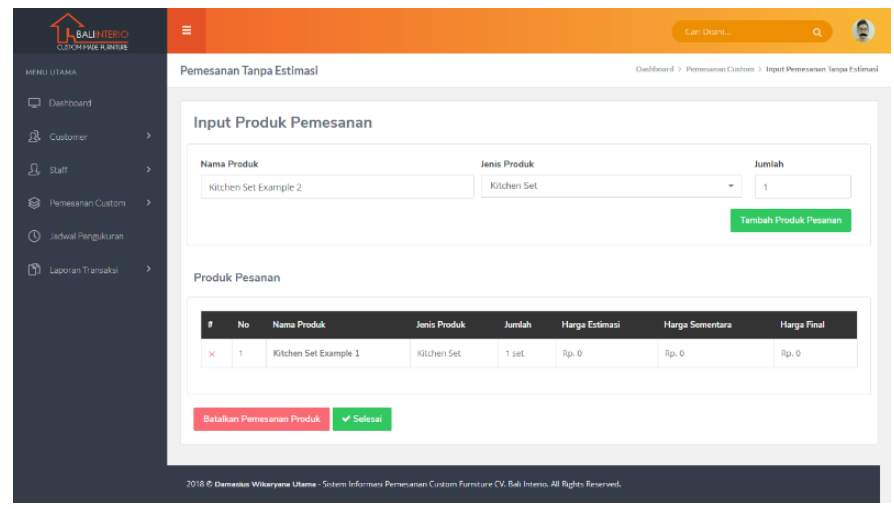

Gambar 15 Halaman Tambah Pemesanan

\section{B.3 Halaman Detail Pemesanan}

Halaman detail pemesanan digunakan pada administrator untuk melihat pemesanan yang telah ditambahkan secara direct/langsung ataupun oleh member/pemesan secara detail. Hasil implementasi halaman detail pemesanan dapat dilihat pada gambar berikut.

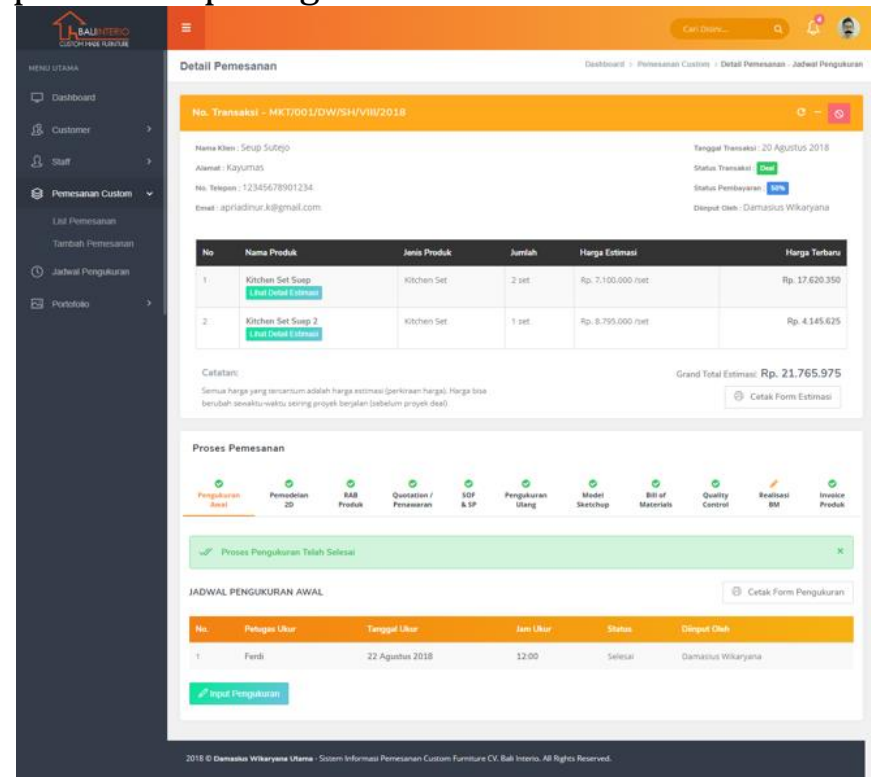

Gambar 16 Halaman Detail Pemesanan

\section{B.4 Halaman Pemodelan 2D}

Halaman pemodelan 2D digunakan oleh administrator khususnya pada bagian desainer untuk menambahkan model 2D. Desainer dapat mengunggah model 2D berbentuk .JPG lebih dari 1 secara bersamaan. Selanjutnya pihak 
manajer dapat melakukan approval terhadap desain tersebut. Hasil implementasi halaman pemodelan 2D dapat dilihat pada gambar berikut.

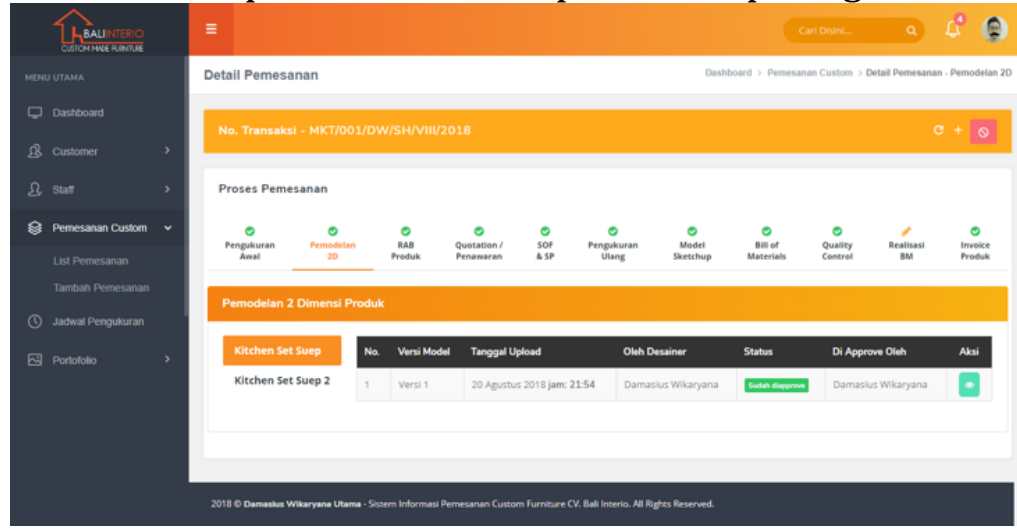

Gambar 17 Halaman Pemodelan 2D

\section{B.5 Halaman RAB}

Halaman RAB merupakan halaman yang digunakan administrator khususnya pada bagian pembuat RAB untuk membuat RAB dari pemesanan produk. Pihak manajer dapat melakukan approval terhadap RAB. Pembuat RAB juga memungkinkan membuat RAB dengan versi yang berbeda. Jika RAB telah ter-approve oleh pihak manajer, maka RAB tersebut akan menjadi acuan untuk pembuatan quotation terhadap customer. Hasil implementasi halaman RAB dapat dilihat pada gambar berikut.

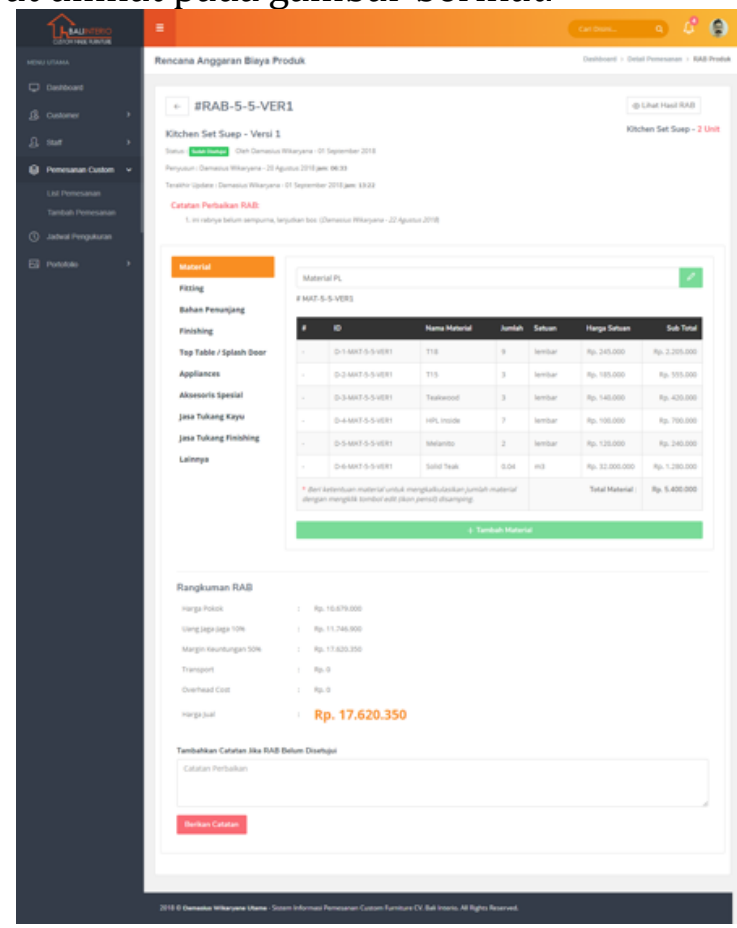

Gambar 18 Halaman RAB

\section{B.6 Halaman Quotation}

Merupakan halaman yang digunakan administrator untuk melihat quotation/penawaran kepada customer berdasarkan RAB yang telah di- 
approve. Quotation juga dapat dicetak dengan kertas A4. Hasil implementasi halaman quotation dapat dilihat pada gambar berikut.

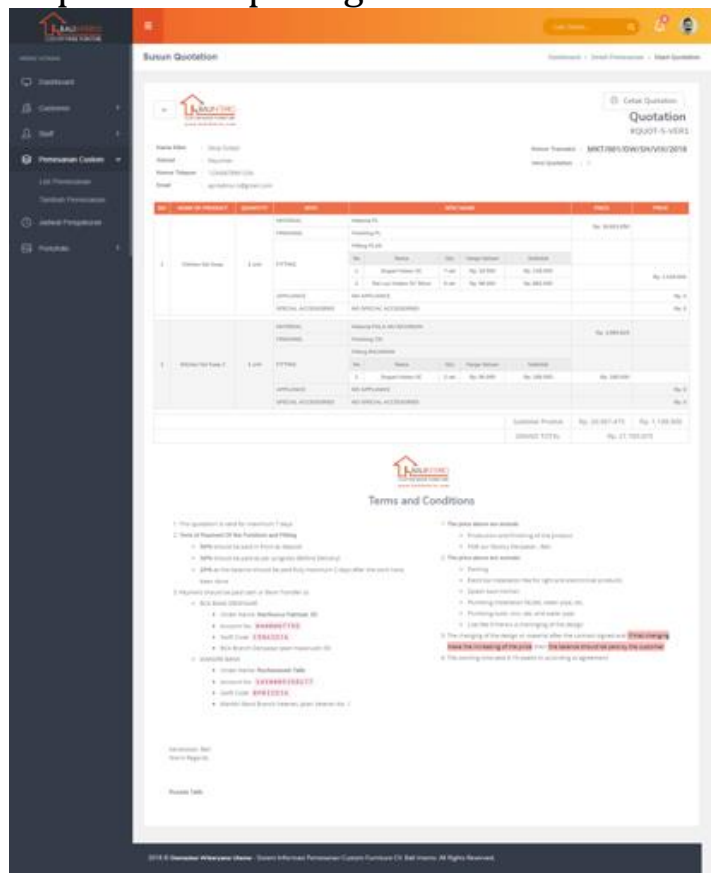

Gambar 19 Halaman Quotation

\section{B.7 Halaman Sales Order dan SPK}

Halaman sales order dan SPK merupakan halaman yang digunakan administrator untuk melihat dokumen sales order secara detail yang selanjutnya dikirim kepada pihak manajer factory sebagai acuan pembuatan produk. Sedangkan SPK terbagi menjadi 2 yaitu SPK untuk tukang kayu dan SPK untuk tukang finishing. SPK diambil dari RAB yang sudah di-approve. Semua dokumen ini dapat dicetak dengan kertas A4. Hasil implementasi halaman sales order dan SPK dapat dilihat pada gambar berikut.

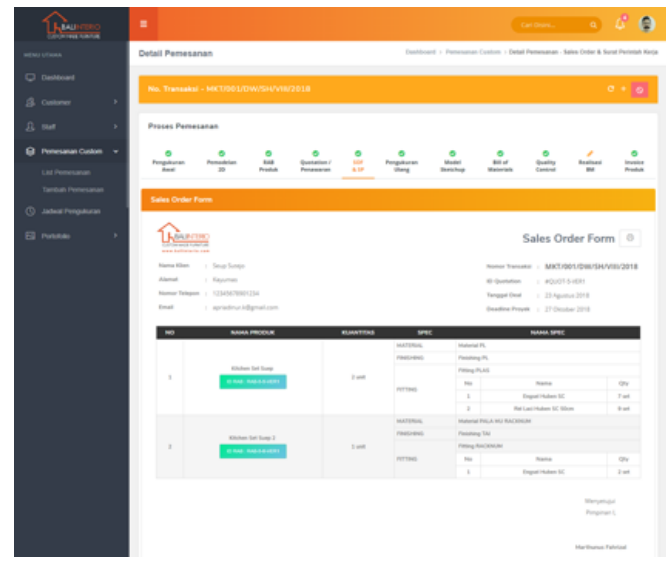

Gambar 20 Halaman Sales Order

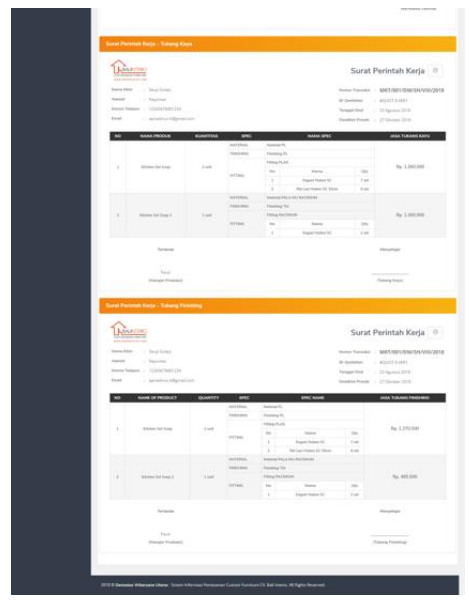

Gambar 21 Halaman Surat Perintah Kerja Tukang 


\section{B.8 Halaman Bill of Material}

Halaman bill of material pada dasarnya adalah halaman yang dapat dicetak sebagai acuan untuk pembelian bahan, material, dan aksesoris pada pemensanan produk. Bill of material di dapatkan berdasarkan RAB yang telah di-approve sebelumnya.

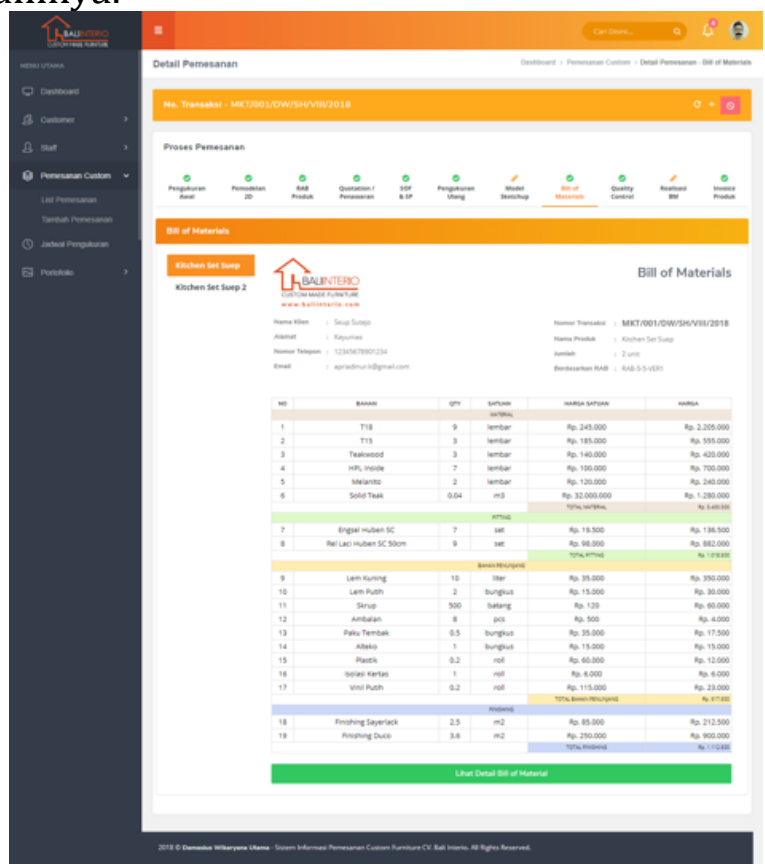

Gambar 22 Halaman Bill of Material

\subsection{Tahap Uji Coba}

Pada tahap ini, penulis melakukan uji coba sistem dengan metode black box testing yaitu pengujian yang didasarkan pada detail aplikasi seperti tampilan aplikasi, fungsi-fungsi yang ada pada aplikasi, dan kesesuaian alur fungsi dengan bisnis proses yang diinginkan oleh customer. Efektifitas sistem informasi pemesanan custom furniture CV. Bali Interio merupakan tahapan yang menunjukan seberapa efektif sistem tersebut dapat memecahkan masalah dan menjadi solusi pada proses bisnis CV. Bali Interio. Penulis menggunakan teknik wawancara mendalam untuk melakukan pengujian efektifitas sistem. Responden yang diwawancara terdiri dari lima pengguna sistem informasi pemesanan custom furniture yaitu general manager, accounting, manager factory, pembuat $\mathrm{RAB}$ dan designer serta 5 pengguna dari sisi member yang dapat dilihat secara detail pada lampiran 42. Masingmasing responden telah melihat dan melakukan uji coba pada sistem informasi pemesanan custom furniture CV. Bali Interio.

Responden pertama yaitu manager CV. Bali Interio menyatakan fiturfitur yang disediakan oleh sistem informasi pemesanan custom furniture CV. Bali Interio sudah cukup lengkap, proses approval, penyajian informasi pemesanan, reporting dan tampilan sistem sudah sesuai kebutuhan. Terdapat pada proses pembuatan rab yang cukup rumit sehingga perlu ditambahkan 
fitur select / pilihan pada material yang didapat dari gudang atau persediaan CV. Bali Interio.

Responden kedua yaitu manager factory $\mathrm{CV}$. Bali Interio menyatakan penyajian informasi mengenai surat perintah kerja (SPK), sales order (SOF), rab, bill of material, model 2D dan 3D cukup baik untuk kebutuhan manager pabrik yang dapat melihat dan mencetak dokumen-dokumen tersebut. Fitur quality control menjadi nilai tambah karena mampu mengubah sampai mana kontrol produk yang dibuat serta mampu mencetak dokumen quality control.

Responden ketiga yaitu accounting $\mathrm{CV}$. Bali Interio menyatakan dalam pembuatan RAB cenderung lebih mudah namun pembuatan menjadi lebih lama diakibatkan dalam penginputan dilakukan dengan meninput teks bukan dengan memilih/select. Pada penyajian informasi rab, bill of material, pembuatan dan pencetakan invoice sudah terasa optimal dan cukup memudahkan accounting. Fitur realisasi rab pun menjadi nilai tambah bagi sistem informasi pemesanan custom furniture CV. Bali Interio karena mampu menyajikan perbandingan antara rab dengan realisasi rab.

Responden keempat yaitu bagian desainer CV. Bali Interio menyatakan pada fitur upload model 2D maupun model 3D berjalan sesuai keinginan yang dikelompokan pada pemesanan dan tercatat. Namun terdapat kekurangan saat mengupload model file berukuran besar yang menjadi gagal saat proses upload. Dari sisi approval, desainer cukup terbantu dengan sistem approval dan catatan yang diberikan oleh manager. Catatan dan file tidak tercecer dan mudah untuk diakses.

Responden kelima yaitu bagian marketing $\mathrm{CV}$. Bali Interio menyatakan sistem informasi pemesanan custom furniture di CV. Bali Interio cukup baik untuk digunakan pada bagian marketing karena dapat menyajikan informasi pemesanan secara detail. Penjadwalan proses pengukuran dapat dilakukan secara mudah. Namun tedapat kekurangan pada bagian notifikasi sistem yang mengharuskan pengguna membuka sistem terlebih dahulu. Notifikasi sistem (reminder jadwal pengukuran, approval rab, approval model, pemesanan deal, pembayaran invoice, dan semua proses penting) dapat dilakukan dengan pengiriman email ke pengguna sehingga pengguna dapat melihat perkembangan pemesanan.

\section{SIMPULAN}

Sistem informasi pemesanan custom furniture CV. Bali Interio dirancang untuk menjawab permasalahan pada proses bisnis custom furniture CV. Bali Interio yaitu pembuatan dokumen secara cepat dan terstruktur, penyajian informasi yang akurat dan dapat melakukan pemesanan seacara online. Alur sistem dirancang menggunakan flowchart, DFD dan ERD yang kemudian diimplementasikan dengan bahasa pemrograman PHP dan basis data MySQL. Sistem informasi custom furniture ini kemudian memuat fitur-fitur untuk kebutuhan proses bisnis pada CV. Bali Interio seperti pembuatan quotation secara otomatis, invoice, $\mathrm{RAB}$, quality control, realisasi $\mathrm{RAB}$, pemodelan 
dengan sistem versi, penjadwalan proses pengukuran serta dapat melakukan pemesanan online.

Penulis melakukan wawancara kepada 5 pengguna sistem informasi custom furniture untuk memvalidasi efektivitas sistem yang telah dibuat. Dari proses wawancara tersebut dapat disimpulkan bahwa sistem informasi pemesanan berbasis website CV. Bali Interio efektif untuk mengatasi permasalahan pada proses bisnis pemesanan custom furniture. Sistem informasi pemesanan custom furniture mampu menjadwalkan pengukuran, membuat dokumen pengukuran, membuat RAB dan pemodelan dengan sistem versi, pembuatan quotation, sales order dan SPK secara otomatis, pembuatan quality control, realisasi RAB dan invoice, serta pemesanan secara online yang dapat dipantau setiap proses pesanannya oleh pemesan.

\section{DAFTAR PUSTAKA}

[1] Budi Nugroho, Nurcahyo and Anwar, Badrul, "Desain Web Menggunakan HTML dan Javascript", Jurnal SAINTIKOM, vol. 4, no. 1.

[2] Damayanti, Rindi and U. Wardati, Indah, "Perancangan Sistem Informasi Pemesanan Dan Pembayaran Kamar Pada Hotel Remaja Pacitan", Indonesian Journal on Networking and Security (IJNS), vol. 3, no. 2, 2014.

[3] Daniel. "Sistem Pemesanan Perakitan Komputer Berbasis Web Pada Toko Master Komputer Bima”. Skripsi Sarjana Komputer, Jurusan Sistem Informasi, Sekolah Tinggi Manajemen Informatika dan Komputer (STMIK) AKAKOM Yogyakarta, Yogyakarta, Indonesia, 2015.

[4] Fatimah, Dina and Maharlika, Febry, "Analisis Penerapan Gaya Desain dan Eksplorasi Bentuk Yang Digunakan Mahasiswa Pada Mata Kuliah Desain Mebel I Fakultas Desain Unikom", Majalah Ilmiah UNIKOM, vol. 12, no. 2, pp169-186.

[5] Galih, Dian. "Sistem Informasi Pemesanan Makanan dan Minuman pada Omahe Café and Resto Berbasis Client Server Dengan Platform Android", Universitas Dian Nuswantoro, Fakultas Ilmu Komputer, Jurusan Sistem Informasi.

[6] Hidayatullah, Priyanto, "Pemrograman WEB", 1st ed. Bandung:Informatika, 2017.

[7] Ibrahim, Ali, "Perancangan Sistem Pemesanan Tiket Pesawat Berbasis Web", Jurnal Sistem Informasi (JSI), ISSN Print : 2085-1588 ISSN Online : 2355-4614, vol. 3, no. 1, pp 320-326, Apr. 2011.

[8] Kusnawi, "Perancangan Sistem Informasi Pemesanan Meja Dan Makanan (Studi Kasus Restoran ABC)", JURNAL DASI ISSN: 1411-3201, vol. 14, no. 1, Mar. 2013.

[9] Pratiwi, Hesti. "Analisis Dan Perancangan Sistem Informasi Akuntansi Penjualan, Penerimaan Kas Dan Pengendalian Internal Pada CV. Chandra Agung Jasa". Universitas Bina Nusantara, 2015.

[10] Puspita, Dwi and Irianti, Siska, "Perancangan Sistem Informasi Pemesanan dan Pembayaran Pada Percetakan Mahardika. Speed Jurnal”, Indonesian Journal on Computer Science, ISSN: 1979-9330, pp. 1-4.

[11] R. Prehanto, Dedy and L. Fitriah, Maya. "Rancang Bangun Sistem Informasi Pemesanan Katering Berbasis Web (Studi Kasus Pada Katering Jelita)", Fakultas Teknik, Universitas Negeri Surabaya. 
Jurnal Sains Komputer \& Informatika (J-SAKTI)

Volume 3 Nomor 1 Maret 2019, pp. 53-67

ISSN:2548-9771/EISSN:2549-7200

http://tunasbangsa.ac.id/ejurnal/index.php/jsakti

[12] Raharjo, Budi, "Mudah Belajar PHP Teknik Penggunaan Fitur-Fitur Baru dalam PHP 5", Bandung:Informatika, 2015.

[13] Salim Akhbar, Rudy Firmansyah and Yulistia. "Sistem Informasi Pemesanan dan Penyewaan Mobil Berbasis Web Pada CV. Louhan Mobilindo". Jurusan Sistem Informasi, STMIK GI MD.

[14] Samiaji Sarosa, SE. and M.Info.Sys., Ph.D, "Metodologi Pengembangan Sistem Informasi", Jakarta Barat: Indeks Jakarta, 2017. 